\title{
Effects of Intermittent Positive Pressure Ventilation on Cardiopulmonary Function in Horses Anesthetized with Total Intravenous Anesthesia Using Combination of Medetomidine, Lidocaine, Butorphanol and Propofol (MLBP-TIVA)
}

\author{
Tomohito ISHIZUKA ${ }^{1)}$, Jun TAMURA ${ }^{1)}$, Tsukasa NAGARO ${ }^{1)}$, Kanako SUDO ${ }^{1)}$, Takaharu ITAMI ${ }^{1)}$, \\ Mohammed Ahamed UMAR ${ }^{1)}$, Kenjirou MIYOSHI ${ }^{1)}$, Tadashi SANO $^{2)}$ and Kazuto YAMASHITA ${ }^{1) *}$ \\ ${ }^{1)}$ Departments of Small Animal Clinical Sciences School of Veterinary Medicine, Rakuno Gakuen University, Ebetsu, Hokkaido 069-8501, \\ Japan \\ 2) Departments of Veterinary Nursing Sciences, School of Veterinary Medicine, Rakuno Gakuen University, Ebetsu, Hokkaido 069-8501, \\ Japan
}

(Received 13 February 2014/Accepted 8 August 2017/Published online in J-STAGE 3 September 2014)

\begin{abstract}
Effects of intermittent positive pressure ventilation (IPPV) on cardiopulmonary function were evaluated in horses anesthetized with total intravenous anesthesia using constant rate infusions of medetomidine (3.5 $\mu \mathrm{g} / \mathrm{kg} / \mathrm{hr})$, lidocaine ( $3 \mathrm{mg} / \mathrm{kg} / \mathrm{hr})$, butorphanol (24 $\mu \mathrm{g} / \mathrm{kg} / \mathrm{hr}$ ) and propofol $(0.1 \mathrm{mg} / \mathrm{kg} / \mathrm{min})$ (MLBP-TIVA). Five horses were anesthetized twice using MLBP-TIVA with or without IPPV at 4-week interval (crossover study). In each occasion, the horses breathed $100 \%$ oxygen with spontaneous ventilation (SB-group, $\mathrm{n}=5$ ) or with IPPV (CV-group, $\mathrm{n}=5$ ), and changes in cardiopulmonary parameters were observed for $120 \mathrm{~min}$. In the SB-group, cardiovascular parameters were maintained within acceptable ranges (heart rate: 33-35 beats/min, cardiac output: 27-30 l/min, mean arterial blood pressure [MABP]: 114-123 mmHg, mean pulmonary arterial pressure [MPAP]: 28-29 mmHg and mean right atrial pressure [MRAP]: 19-21 $\mathrm{mmHg}$ ), but severe hypercapnea and insufficient oxygenation were observed (arterial $\mathrm{CO}_{2}$ pressure $\left[\mathrm{PaCO}_{2}\right]: 84-103 \mathrm{mmHg}$ and arterial $\mathrm{O}_{2}$ pressure $\left.\left[\mathrm{PaO}_{2}\right]: 155-172 \mathrm{mmHg}\right)$. In the $\mathrm{CV}$-group, normocapnea $\left(\mathrm{PaCO}_{2}: 42-50 \mathrm{mmHg}\right)$ and good oxygenation $\left(\mathrm{PaO}_{2}: 395-419\right.$ $\mathrm{mmHg}$ ) were achieved by the IPPV without apparent cardiovascular depression (heart rate: $29-31$ beats/min, cardiac output: $17-21 l / \mathrm{min}$, MABP: 111-123 mmHg, MPAP: 27-30 mmHg and MRAP: 15-16 mmHg). MLBP-TIVA preserved cardiovascular function even in horses artificially ventilated.

KEY WORDS: cardiopulmonary function, horse, intermittent positive pressure ventilation (IPPV), MLBP-TIVA
\end{abstract}

doi: 10.1292/jvms.14-0077; J. Vet. Med. Sci. 76(12): 1577-1582, 2014

Morbidity and mortality in clinical equine anesthesia are considerably greater than in other domestic species, and this is usually caused by hypotension and hypoventilation during anesthesia [18]. To improve outcomes of equine anesthesia, many researchers have tried to develop anesthetic protocols that can provide less cardiopulmonary depression $[4,6,21$, 25-27]. We earlier reported that total intravenous anesthesia using combination of medetomidine, lidocaine, butorphanol and propofol (MLBP-TIVA) provides effective general anesthesia while preserving cardiovascular function and with good recovery in horses, but hypercapnea was observed under spontaneous breathing [4].

In the current equine practice, intermittent positive pressure ventilation (IPPV) is widely used to treat hypercapnea during general anesthesia. However, it can result in decreases in cardiac output (CO), systemic arterial blood pressure and oxygen delivery in horses [19]. The IPPV directly

\footnotetext{
*Correspondence to: Yamashita, K., Departments of Small Animal Clinical Sciences, School of Veterinary Medicine, Rakuno Gakuen University, Ebetsu, Hokkaido 069-8501, Japan.

e-mail: yamasita@rakuno.ac.jp

(C)2014 The Japanese Society of Veterinary Science

This is an open-access article distributed under the terms of the Creative Commons Attribution Non-Commercial No Derivatives (by-nc-nd) License $<$ http://creativecommons.org/licenses/by-nc-nd/3.0/>.
}

increases intrathoracic pressure during inspiration and then affects cardiovascular function by reducing venous return $[3$, $5,9,21]$. As mentioned above, cardiovascular function can be preserved in horses anesthetized with MLBP-TIVA [4]. It is expected that hypercapnea during MLBP-TIVA can be effectively treated by IPPV without apparent cardiovascular depression.

The purpose of the present study was to evaluate effects of the IPPV on cardiopulmonary function in horses anesthetized with MLBP-TIVA. We hypothesized that the combination of MLBP-TIVA and IPPV will produce a good cardiopulmonary status in horses.

\section{MATERIALS AND METHODS}

Experimental animals: Five healthy horses weighing 406 to $552 \mathrm{~kg}(472 \pm 55 \mathrm{~kg}$ [mean \pm standard deviation] at the first occasion of a crossover study) and aged 1 to 20 years ( $7.4 \pm 8.4$ years) were used for this crossover study (Table 1). Their right carotid arteries had been surgically raised to a subcutaneous position at least 1 month prior to the first occasion of a crossover study under general anesthesia. The horses were anesthetized twice using MLBP-TIVA with or without IPPV at 4-week interval. In each occasion, the horses breathed $100 \%$ oxygen with spontaneous ventilation (SB-group, $\mathrm{n}=5$ ) or with IPPV (CV-group, $\mathrm{n}=5$ ). Food 
Table 1. Horses used in the present study

\begin{tabular}{ccccc}
\hline & Breed & $\begin{array}{c}\text { Age } \\
(\text { years old })\end{array}$ & $\begin{array}{c}\text { Body weight } \\
(\mathrm{kg})\end{array}$ & Sex \\
\hline No.1 & Thoroughbred & 12 & 552 & Female \\
No.2 & Anglo-Arab & 20 & 456 & Gelding \\
No.3 & Thoroughbred & 1 & 406 & Female \\
No.4 & Thoroughbred & 2 & 497 & Male \\
No.5 & Thoroughbred & 2 & 449 & Male \\
\hline Mean \pm Standard deviation & $7.4 \pm 8.4$ & $472 \pm 55$ & \\
\hline
\end{tabular}

but not water, was withheld from horses for $12 \mathrm{hr}$ before anesthesia. The horses were owned by Rakuno Gakuen University and were cared for according to the principles of the "Guide for the Care and Use of Laboratory Animals" prepared by Rakuno Gakuen University. The Animal Care and Use Committee of Rakuno Gakuen University approved the study (approved No. VH21C11).

Experimental protocol: Initially, all horses were instrumented with introducers and catheters for measuring cardiopulmonary parameters under MLBP-TIVA with spontaneous breathing. Baseline values of cardiopulmonary parameters were determined in the horses following the instrumentation. Then, the horses continued to breathe spontaneously (the SBgroup) or were mechanically ventilated by IPPV ( 6 breaths/ min, the ratio of expiratory time: inspiratory time $=4: 1)$ to maintain arterial $\mathrm{CO}_{2}$ pressure $\left(\mathrm{PaCO}_{2}\right)$ within $40-50 \mathrm{mmHg}$ (the CV-group) using a large animal circle anesthetic system (Model 2800 Large Animal Anesthesia Ventilator System, Mallard Medical, Inc., Redding, CA, U.S.A.). In both groups, MLBP-TIVA was maintained for additional $120 \mathrm{~min}$, and the cardiopulmonary parameters were determined at 20 min interval.

MLBP-TIVA: The horses were pre-medicated with an intravenous administration (IV) of medetomidine $(5 \mu \mathrm{g}$ ) kg; Domitor, Nippon Zenyaku Kogyo Co., Ltd., Koriyama, Japan) and butorphanol (20 $\mu \mathrm{g} / \mathrm{kg}$; Vetorphale, Meiji Seika Pharma Co., Ltd., Tokyo, Japan) via a 14-gauge, 13.3-cm catheter (BD Angiocath, Becton Dickinson and Co., Sandy, UT, U.S.A.) placed in the left jugular vein and restrained in a swing-door induction system. Anesthesia was induced by co-administration of lidocaine ( $1 \mathrm{mg} / \mathrm{kg}, \mathrm{IV} ; 2 \%$ Xylocaine: AstraZeneca, Osaka, Japan) and propofol (3 mg/kg, IV; $\%$ Propofol Injection "Maruishi," Maruishi Pharmaceutical Co., Ltd., Osaka, Japan). After the induction of anesthesia, the horses were orotracheally intubated and positioned in the left lateral recumbency on an inflated airbed surgical table (SNELL2000, Snell Veterinary Systems, Castle Cary, U.K.). The endotracheal tube was connected to the large animal circle anesthetic system that delivered 100\% oxygen $(5 \mathrm{l} / \mathrm{min})$. Anesthesia was maintained by MLBP-TIVA consisting of constant rate infusions of medetomidine (3.5 $\mu \mathrm{g} / \mathrm{kg} / \mathrm{hr})$, lidocaine (3 $\mathrm{mg} / \mathrm{kg} / \mathrm{hr})$, butorphanol $(24 \mu \mathrm{g} / \mathrm{kg} /$ $\mathrm{hr})$ and propofol $(0.1 \mathrm{mg} / \mathrm{kg} / \mathrm{min})$. Briefly, a drug mixture of medetomidine $(17.5 \mu \mathrm{g} / \mathrm{m} l)$, lidocaine $(15 \mathrm{mg} / \mathrm{ml})$ and butorphanol $(120 \mathrm{mg} / \mathrm{m} l)$ in saline was infused at a rate of $0.2 \mathrm{ml} / \mathrm{kg} / \mathrm{hr}$ using an infusion pump (STC-521, Terumo,
Tokyo, Japan), and simultaneously $2 \%$ propofol was infused at a rate of $0.3 \mathrm{ml} / \mathrm{kg} / \mathrm{hr}$ using a syringe pump (TOP-2200, TOP Corporation, Tokyo, Japan). Lactated Ringer's solution (Solulact, Terumo) was administered IV at a rate of $10 \mathrm{~m} l /$ $\mathrm{kg} / \mathrm{hr}$ to the horses during anesthesia.

Instrumentation and measuring cardiopulmonary parameters: Once the horses were positioned in the left lateral recumbency on the surgical table, the cervical area for placement of introducers and catheters was clipped and aseptically prepared. An 18-gauge catheter (Supercath, Medikit Co., Ltd., Tokyo, Japan) was placed in the raised right carotid artery. An 8-french introducer (Exacta percutaneous sheath introducer, Ohmeda, Swindon, U.K.) was placed in the right jugular vein. A 9-french introducer (Exacta percutaneous sheath introducer, Ohmeda) was placed in the right jugular vein $30 \mathrm{~cm}$ cranial to the 8 -french introducer. A 7-french thermodilution catheter (Criti-Cath SP-5107, Ohmeda) was placed in the pulmonary artery through the 8 -french introducer. An 8-french catheter $100 \mathrm{~cm}$ in length (Intervec super guiding catheter, Fuji Systems Co., Tokyo, Japan) was placed in the right atrium through the 9-french introducer. We determined the position of these catheters where a typical pressure waveform was recorded constantly at the tip of each catheter. Furthermore, the distance between the tip of thermodilution catheter and the 8-french catheter was adjusted to $40-50 \mathrm{~cm}$.

Arterial blood samples were anaerobically collected from the 18-gauge catheter placed in the raised right carotid artery into a heparinized syringe, and $\mathrm{PaCO}_{2}(\mathrm{mmHg})$, arterial $\mathrm{O}_{2}$ pressure $\left(\mathrm{PaO}_{2} ; \mathrm{mmHg}\right)$ and arterial $\mathrm{pH}(\mathrm{pHa})$ were determined immediately using a blood gas analyzer (GEM Premier 3000, Instrumentation Laboratory, Tokyo, Japan). Base-apex electrocardiography, heart rate (HR; beats/min), arterial blood pressure (ABP; $\mathrm{mmHg}$ ), pulmonary artery pressure (PAP; $\mathrm{mmHg}$ ), right atrial pressure (RAP; $\mathrm{mmHg}$ ) and $\mathrm{CO}$ were recorded using a computer based data acquisition system (DS-7210, Fukuda Denshi, Tokyo, Japan). ABP, PAP and RAP were measured by connecting catheters placed in the right carotid artery, pulmonary artery and right atrium to pressure transducers (CDX-A90, Cobe Laboratories, Tokyo, Japan), respectively. These pressure transducers were placed at the level of the sternum.

$\mathrm{CO}$ was measured by a thermodilution technique $[6,11$, $21,25-27]$. A volume of $40 \mathrm{ml}$ of a $5 \%$ dextrose solution at $0^{\circ} \mathrm{C}$ that was injected manually for approximately $2 \mathrm{sec}$ through the 8-french catheter placed in the right atrium. $\mathrm{CO}$ was measured at least 3 times, and the mean value was calculated. Cardiac index (CI) was calculated from the body weight and $\mathrm{CO}$; stroke volume (SV) was calculated from the $\mathrm{HR}$ and $\mathrm{CO}$; and systemic vascular resistance (SVR) was determined from the mean ABP (MABP), CO and the mean RAP (MRAP). CI, SV and SVR were calculated by inserting values into formulas below [6, 21, 25-27].

$\mathrm{CI}(\mathrm{m} l / \mathrm{min} / \mathrm{kg})=\mathrm{CO} /$ Body weight $\times 1,000$

$\mathrm{SV}(\mathrm{m} l /$ beat $)=\mathrm{CO} / \mathrm{HR} \times 1,000$

$\operatorname{SVR}\left(\right.$ dynes $\left.\cdot \mathrm{sec} \cdot \mathrm{cm}^{-5}\right)=($ MABP-MRAP $) \times 80 / \mathrm{CO}$

Statistical analysis: All data are shown as the mean and standard deviation (mean $\pm \mathrm{SD}$ ). Repeated-measures 
Table 2. Changes in cardiopulmonary parameters in horses anesthetized with MLBP-TIVA with (CV-group) or without (SB-group) controlled positive-pressure ventilation

\begin{tabular}{|c|c|c|c|c|c|c|c|}
\hline \multirow{2}{*}{ Variable } & \multirow{2}{*}{ Baseline } & \multicolumn{6}{|c|}{ Minutes after induction of anesthesia } \\
\hline & & 20 & 40 & 60 & 80 & 100 & 120 \\
\hline \multicolumn{8}{|l|}{ HR (beats/min) ${ }^{\dagger}$} \\
\hline SB-group & $36 \pm 5$ & $34 \pm 4$ & $35 \pm 4$ & $35 \pm 2$ & $35 \pm 2$ & $33 \pm 3$ & $33 \pm 2$ \\
\hline CV-group & $36 \pm 5$ & $31 \pm 4$ & $31 \pm 4^{*}$ & $31 \pm 4^{*}$ & $31 \pm 3^{*}$ & $29 \pm 4^{*}$ & $30 \pm 4^{*}$ \\
\hline \multicolumn{8}{|l|}{ MABP $(\mathrm{mmHg})$} \\
\hline SB-group & $108 \pm 13$ & $114 \pm 11$ & $116 \pm 12$ & $122 \pm 6$ & $121 \pm 6$ & $123 \pm 4$ & $120 \pm 2$ \\
\hline CV-group & $98 \pm 16$ & $111 \pm 17$ & $119 \pm 13$ & $123 \pm 11$ & $120 \pm 12$ & $119 \pm 10$ & $119 \pm 8$ \\
\hline \multicolumn{8}{|l|}{ MPAP $(\mathrm{mmHg})$} \\
\hline SB-group & $29 \pm 7$ & $29 \pm 6$ & $29 \pm 6$ & $28 \pm 5$ & $28 \pm 6$ & $29 \pm 6$ & $28 \pm 6$ \\
\hline CV-group & $31 \pm 5$ & $30 \pm 2$ & $30 \pm 6$ & $30 \pm 3$ & $29 \pm 3$ & $28 \pm 2$ & $27 \pm 2$ \\
\hline \multicolumn{8}{|l|}{ MRAP (mmHg) } \\
\hline SB-group & $21 \pm 11$ & $21 \pm 11$ & $20 \pm 9$ & $19 \pm 6$ & $19 \pm 5$ & $20 \pm 7$ & $20 \pm 10$ \\
\hline CV-group & $15 \pm 4$ & $16 \pm 4$ & $17 \pm 4$ & $17 \pm 4$ & $15 \pm 4$ & $15 \pm 4$ & $15 \pm 4$ \\
\hline \multicolumn{8}{|l|}{$\mathrm{CO}(\mathrm{ml} / \mathrm{min})^{\dagger \dagger}$} \\
\hline SB-group & $26 \pm 3$ & $29 \pm 4$ & $29 \pm 6$ & $30 \pm 9$ & $27 \pm 3$ & $30 \pm 7$ & $29 \pm 4$ \\
\hline CV-group & $26 \pm 4$ & $21 \pm 2 *$ & $19 \pm 4 *$ & $18 \pm 3^{*}$ & $17 \pm 3^{*}$ & $17 \pm 3^{*}$ & $17 \pm 2 *$ \\
\hline \multicolumn{8}{|l|}{$\mathrm{CI}(\mathrm{m} / / \mathrm{min} / \mathrm{kg})^{\dagger \dagger}$} \\
\hline SB-group & $56 \pm 7$ & $61 \pm 8$ & $60 \pm 8$ & $62 \pm 12$ & $58 \pm 5$ & $64 \pm 9$ & $61 \pm 6$ \\
\hline CV-group & $56 \pm 7$ & $45 \pm 4^{*}$ & $40 \pm 8^{*}$ & $39 \pm 7 *$ & $37 \pm 6^{*}$ & $37 \pm 8^{*}$ & $36 \pm 5^{*}$ \\
\hline \multicolumn{8}{|l|}{$\mathrm{SV}(\mathrm{m} l / \text { beat })^{\dagger}$} \\
\hline SB-group & $731 \pm 68$ & $764 \pm 122$ & $740 \pm 132$ & $779 \pm 184$ & $732 \pm 80$ & $829 \pm 154$ & $774 \pm 136$ \\
\hline CV-group & $746 \pm 137$ & $693 \pm 104$ & $601 \pm 96^{*}$ & $593 \pm 56^{*}$ & $558 \pm 36^{*}$ & $594 \pm 43^{*}$ & $561 \pm 54^{*}$ \\
\hline \multicolumn{8}{|c|}{ SVR $\left(\text { dynes } \cdot \mathrm{sec} \cdot \mathrm{cm}^{-5}\right)^{\dagger \dagger}$} \\
\hline SB-group & $286 \pm 56$ & $259 \pm 60$ & $264 \pm 80$ & $270 \pm 70$ & $271 \pm 40$ & $247 \pm 45$ & $251 \pm 56$ \\
\hline CV-group & $256 \pm 58$ & $355 \pm 36$ & $443 \pm 65^{*}$ & $472 \pm 81 *$ & $494 \pm 65^{*}$ & $486 \pm 95^{*}$ & $500 \pm 65^{*}$ \\
\hline \multicolumn{8}{|l|}{ RR (breaths/min) } \\
\hline SB-group & $5 \pm 4$ & $6 \pm 5$ & $7 \pm 7$ & $6 \pm 5$ & $6 \pm 7$ & $5 \pm 4$ & $5 \pm 4$ \\
\hline CV-group & $4 \pm 4$ & 6 & 6 & 6 & 6 & 6 & 6 \\
\hline \multicolumn{8}{|l|}{$\mathrm{pHa}$} \\
\hline SB-group & $7.29 \pm 0.06$ & $7.28 \pm 0.09$ & $7.30 \pm 0.07$ & $7.28 \pm 0.08$ & $7.25 \pm 0.10$ & $7.24 \pm 0.08$ & $7.24 \pm 0.07$ \\
\hline CV-group & $7.27 \pm 0.10$ & $7.45 \pm 0.06$ & $7.49 \pm 0.06$ & $7.50 \pm 0.05$ & $7.51 \pm 0.05$ & $7.52 \pm 0.05$ & $7.53 \pm 0.05$ \\
\hline \multicolumn{8}{|l|}{$\mathrm{PaCO}_{2}(\mathrm{mmHg})^{\dagger \dagger}$} \\
\hline SB-group & $79 \pm 10$ & $84 \pm 20$ & $83 \pm 16$ & $87 \pm 19$ & $100 \pm 28$ & $101 \pm 22$ & $103 \pm 21$ \\
\hline CV-group & $83 \pm 27$ & $50 \pm 6^{*}$ & $46 \pm 5^{*}$ & $44 \pm 3^{*}$ & $44 \pm 5^{*}$ & $43 \pm 4^{*}$ & $42 \pm 5^{*}$ \\
\hline \multicolumn{8}{|l|}{$\mathrm{PaO}_{2}(\mathrm{mmHg})^{\dagger \dagger}$} \\
\hline SB-group & $187 \pm 105$ & $167 \pm 96$ & $172 \pm 88$ & $169 \pm 89$ & $155 \pm 66$ & $161 \pm 72$ & $168 \pm 66$ \\
\hline $\mathrm{CV}$-group & $209 \pm 123$ & $395 \pm 103 *$ & $401 \pm 104 *$ & $407 \pm 88^{*}$ & $419 \pm 90^{*}$ & $401 \pm 79^{*}$ & $403 \pm 80^{*}$ \\
\hline
\end{tabular}

Data are expressed as mean \pm standard deviation. Significant difference in changes between the groups by repeated measures ANOVA: ${ }^{\dagger} P<0.05$, ${ }^{\dagger} P<0.01$, *: significant difference in the same time data compared to the SB-group by paired $t$-test $(P<0.05)$. HR: heart rate, MABP: mean arterial pressure, MPAP: mean pulmonary artery pressure, MRAP: mean right artial pressure, CO: cardiac output, CI: cardiac index, SV: stroke volume, SVR: systemic vascular resistance, $\mathrm{RR}$ : respiratory rate, $\mathrm{pHa}$ a arterial blood $\mathrm{pH}, \mathrm{PaCO}_{2}$ : arterial carbon dioxide tension, $\mathrm{PaO}_{2}$ : arterial oxygen tension.

ANOVA was used to analyze changes in cardiopulmonary parameters. When a significant difference was detected in the cardiopulmonary parameters between the groups by the ANOVA, the data determined at the same time were compared using paired $t$-test between the groups. The paired $t$-test was also used to compare the times during recovery from anesthesia between the groups. $P<0.05$ was considered statistically significant.

\section{RESULTS}

All horses were smoothly maintained anesthesia for total of $180 \mathrm{~min}$ (60 min for instrumentation and additional 120 min for measuring the cardiopulmonary parameters) with MLBP-TIVA. No complication during MLBP-TIVA was observed in the horses following the 2 experimental occasions.

Baseline values of cardiopulmonary parameters: Changes in cardiovascular parameters during MLBP-TIVA are shown in Table 2. The baseline values were determined at $60 \mathrm{~min}$ after the induction of anesthesia in both groups. There was no significant difference in the baseline values of cardiopulmonary parameters between the groups. The baseline values of cardiopulmonary parameters were within normal ranges $[10,19]$, except for $\mathrm{PaCO}_{2}$ and $\mathrm{pHa}$. Severe respiratory acidosis and hypercapnea developed at the baseline values determination in both groups. 
Changes in cardiopulmonary parameters: In the SBgroup, consistent severe respiratory acidosis and hypercapnea with insufficient oxygenation were observed $(\mathrm{pHa}$ : 7.236-7.298, $\mathrm{PaCO}_{2}: 83-103 \mathrm{mmHg}$ and $\mathrm{PaO}_{2}: 155-172$ $\mathrm{mmHg}$ ) during the period of additional 120 min anesthesia with MLBP-TIVA. In the CV-group, a significant decrease in $\mathrm{PaCO}_{2}(42-50 \mathrm{mmHg}, P=0.001)$ and increases in $\mathrm{PaO}_{2}$ (395-419 mmHg, $P=0.005)$ and $\mathrm{pHa}(7.45-7.53, P=0.001)$ were observed following the start of controlled positivepressure ventilation. The cardiovascular parameters were maintained within acceptable ranges in both groups. There was no significant difference in MABP, MRAP and MPAP between the groups. On the other hand, $\mathrm{HR}, \mathrm{CO}, \mathrm{CI}$ and $\mathrm{SV}$ were significantly lower in the $\mathrm{CV}$-group compared to the SB-group $(P=0.02, P=0.004, P=0.0004$ and $P=0.02$, respectively). The SVR was significantly higher in the $\mathrm{CV}$-group compared to the SB-group $(P=0.0007)$.

Recovery from anesthesia: Recovery from anesthesia was smooth and without incident in both groups. The horses were extubated at $28 \pm 11 \mathrm{~min}$ and stood at $51 \pm 9 \mathrm{~min}$ after the cessation of anesthesia in the SB-group. The horses were extubated at $34 \pm 8 \mathrm{~min}$ and stood at $64 \pm 10 \mathrm{~min}$ in the CVgroup. There was no significant difference in the extubation times $(P=0.11)$, but a significant difference was detected in the standing times $(P=0.02)$.

\section{DISCUSSION}

In the present study, we anesthetized 5 healthy horses including young ( 1 year old) and aged (20 years old) individuals. Therefore, it is supposed that a significant difference in the individual capacity of cardiopulmonary function would arise from large variation in the age of these horses. This was the limitation of the present study, and there was a possibility that the un-uniform aging population of these horses would influence the results of cardiopulmonary parameters recorded during the MLBP-TIVA. However, our data indicated that the IPPV could provide a marked improvement in the status of ventilation and oxygenation without any apparent cardiovascular depression in these horses. Therefore, it is expected that MLBP-TIVA can preserve cardiovascular function in horses including young and aged horses, even when the horses were artificially ventilated.

We previously reported that MLBP-TIVA provided a stable anesthesia in 10 horses undergoing experimental surgical translocation of carotid artery and mean infusion rate of propofol required for maintaining surgical depth of anesthesia was $0.10 \mathrm{mg} / \mathrm{kg} / \mathrm{min}$ [4]. Based on this previous report, we adopted $0.1 \mathrm{mg} / \mathrm{kg} / \mathrm{min}$ of propofol infusion rate to mimic a surgical plane of anesthesia in the present study. Therefore, it could be inferred that our horses were anesthetized at the surgical depth of anesthesia for total $180 \mathrm{~min}$ (60 min for instrumentation and $120 \mathrm{~min}$ for the cardiopulmonary measurements) with MLBP-TIVA.

The cardiovascular parameters recorded in the horses of SB group were similar to those reported in standing conscious healthy resting horses [6, 21, 25-27], except for the MRAP. Medetomidine, one of the component drugs of
MLBP-TIVA, produces a dose-dependent vasoconstriction by stimulating $\alpha_{2}$-adrenoceptors on peripheral vasculatures $[10,26]$, and consequently, medetomidine induced peripheral vasoconstriction may be a factor contributing to the well maintained ABP and decreases in the $\mathrm{CO}, \mathrm{CI}$ and $\mathrm{SV}$ during MLBP-TIVA. It is reported that moderate $\left(\mathrm{PaCO}_{2} 60-70\right.$ $\mathrm{mmHg})$ and severe $\left(\mathrm{PaCO}_{2} 75-80 \mathrm{mmHg}\right)$ hypercapnea may augment $\mathrm{CO}$ via vasodilation and epinephrine release in horses [22]. Although we did not measure plasma concentration of epinephrine, it is supposed that the increases in HR (33-35 beats $/ \mathrm{min}), \mathrm{CO}$ (27-30 l/min), CI (57-62 $\mathrm{ml} / \mathrm{min} / \mathrm{kg}$ ) and SV (732-830 $\mathrm{ml} /$ beat) and decrease in the SVR (246270 dynes $\cdot \mathrm{sec} \cdot \mathrm{cm}^{-5}$ ) were produced by the hypercapnea via vasodilation and epinephrine release in the SB-group. The medetomidine-induced vasoconstriction might be offset by the hypercapnea-induced vasodilation.

On the other hand, the vasodilation and epinephrine release induced by the hypercapnea might disappear following normalizing $\mathrm{PaCO}_{2}$ (i.e., normocapnea) and the medetomidine-induced vasoconstriction that appeared in the $\mathrm{CV}$ group. Consequently, the ABP was equally well maintained in the both groups (114-123 mmHg: SB-group and 111-123 mmHg: CV-group), although the HR (29-31 beats/min), CO (17-21 l/min), CI (36-46 $\mathrm{ml} / \mathrm{min} / \mathrm{kg})$ and SV (558-693 $\mathrm{ml} /$ beat) decreased significantly in the $\mathrm{CV}$-group, compared to the SB-group. However, the CO, CI and SV in the CVgroup were somewhat less or better than those reported in artificially ventilated horses under sevoflurane anesthesia (CO: $19.2 \pm 2.0 \mathrm{l} / \mathrm{min}$ and CI: $44.9 \pm 4.3 \mathrm{ml} / \mathrm{kg} / \mathrm{min}$ [23], CI: $26-30 \mathrm{ml} / \mathrm{kg} / \mathrm{min}$ and SV: $407-467 \mathrm{ml} /$ beat [24], CO: 22-29 l/min, CI: 46-62 $\mathrm{ml} / \mathrm{kg} / \mathrm{min}$ and SV: 594-752 $\mathrm{ml}$ beat [25]). It is concluded that the cardiovascular function during MLBP-TIVA was well maintained in spontaneously breathing horses and was preserved within acceptable range in artificially ventilated horses.

In the present study, severe hypercapnea $\left(\mathrm{PaCO}_{2}: 83-103\right.$ $\mathrm{mmHg}$ ) was observed with lowered respiratory rate (RR: 5-7 breaths/min) in the horses of the SB-group, consistent with our previous report [4]. Significant decreases in respiratory rate and increase in $\mathrm{PaCO}_{2}$ were similarly observed when $\alpha_{2}$-adrenoceptor agonists, such as xylazine $(1 \mathrm{mg} / \mathrm{kg}$, IV), detomidine (10-40 $\mu \mathrm{g} / \mathrm{kg}, \mathrm{IV})$, medetomidine (3-10 $\mu \mathrm{g}$ / $\mathrm{kg}, \mathrm{IV})$ [26], propofol (8 mg/kg, IV) alone [12], propofol $(2 \mathrm{mg} / \mathrm{kg}$, IV) following the premedication with xylazine $(0.5-1.0 \mathrm{mg} / \mathrm{kg}, \mathrm{IV})$ or detomidine (10-30 $\mu \mathrm{g} / \mathrm{kg}, \mathrm{IV})$ [7], and a combination of detomidine $(20 \mu \mathrm{g} / \mathrm{kg}$, IV) and butorphanol (25 $\mu \mathrm{g} / \mathrm{kg}$, IV) [15] were administered to horses. On the other hand, it is reported that a constant rate infusion of lidocaine $(3 \mathrm{mg} / \mathrm{kg} / \mathrm{hr})$ did not produce respiratory depression in horses [23]. Therefore, it is supposed that severe hypercapnea with lowered respiratory rate was induced by the respiratory depressant effect produced by medetomidine, butorphanol and propofol in the horses of the SB-group.

Although our horses breathed $100 \%$ oxygen, insufficient oxygenation $\left(\mathrm{PaO}_{2}: 155-171 \mathrm{mmHg}\right)$ was observed during the entire period of MLBP-TIVA in the horses of SB-group. Anesthetized horses develop a large alveolar-arterial oxygen difference as a result of postural effects in the distribution of 
blood flow and especially ventilation [2, 13-15]. Ventilation of the dependent lung is impeded mechanically, and functional residual capacity (FRC) is reduced when horses are anesthetized and become recumbent [13]. The reduction in FRC in the recumbent anesthetized horses presumably leads to airway closure in dependent regions, which is responsible in part for uneven distribution of ventilation, leading to ventilation perfusion inequalities and hypoxemia $[1,2,16]$. Gas exchange is accomplished by the close approximation of air and blood in the peripheral airspaces of the lung, and therefore, the matching of ventilation to blood flow (V/Q) is the most important determinant of gas exchange [16]. In the present study, it is supposed that appropriate blood flows were provided in the peripheral airspaces, because cardiovascular parameters were maintained within normal ranges [17] in the horses of SB-group. On the other hand, decreased ventilation was demonstrated by the hypercapnea with lowered respiratory rate in the horses, as mentioned above. Therefore, it is inferred that the V/Q mismatch induced by decreased ventilation may be responsible for the insufficient oxygenation observed in the horses of SB-group.

Generally, hypercapnea during anesthesia is widely treated with the IPPV in horses [5]. As we expected, the IPPV provided a marked improvement in the status of ventilation and oxygenation in the horses anesthetized with MLBP-TIVA. It is pointed out that the IPPV may contribute to decreases in $\mathrm{CO}$ and $\mathrm{ABP}$ secondary to increases in intrathoracic pressure, which can decrease venous return $[3,5,9$, 19]. In the present study, the cardiovascular parameters (i.e., HR, MABP, CO, CI, SV, MRAP and MPAP) were maintained within acceptable ranges even in the horses artificially ventilated with the IPPV. However, significant decreases in the $\mathrm{HR}, \mathrm{CO}, \mathrm{CI}$ and $\mathrm{SV}$ were detected in the CV-group, compared to those in the SB-group. Therefore, cardiovascular function may be disturbed by the IPPV, but may not fall into apparent cardiovascular depression in horses anesthetized with MLBP-TIVA. It is observed that MLBP-TIVA preserved cardiovascular function even in horses artificially ventilated in this study.

In the present study, recovery from anesthesia was somewhat delayed in the CV-group. It is reported that the extraction of propofol by the lung is not affected by mechanical ventilation in cats [8]. On the other hand, it is reported that propofol concentrations can be increased by positive endexpiratory pressure (PEEP) in human patients anesthetized with $60 \%$ nitrous oxide in oxygen, fentanyl and continuous infusion of propofol [20]. In the study, increased plasma propofol concentration was accompanied with decreases in $\mathrm{CO}$, and effective liver blood flow after PEEP was applied [20]. In the present study, the CO was significantly lower in the CV-group, compared to the SB-group. It is speculated that the delayed recovery in the CV-group might be caused by higher plasma propofol concentrations at the cessation of anesthesia, although we did not measure the plasma concentration of propofol. Therefore, close attention should be paid to the depth of anesthesia in order to avoid overdosing of propofol in artificially ventilated horses.

In conclusion, cardiovascular functions were maintained within acceptable ranges during MLBP-TIVA in horses, and IPPV is useful for improving hypercapnea and oxygenation during MLBP-TIVA. MLBP-TIVA preserved cardiovascular function even in horses artificially ventilated.

ACKNOWLEDGMENT. This research was supported by JSPS KAKENHI Grant Number 22580366.

\section{REFERENCES}

1. Hall, L. W. 1971. Disturbances of cardiopulmonary function in anaesthetised horses. Equine Vet. J. 3: 95-98. [Medline] [CrossRef]

2. Hall, L. W., Gillespie, J. R. and Tyler, W. S. 1968. Alveolararterial oxygen tension differences in anaesthetized horses. $B r$. J. Anaesth. 40: 560-568. [Medline] [CrossRef]

3. Hubbell, J. A. E. 2007. Horses. pp. 717-729. In: Lumb \& Jones' Veterinary Anesthesia, 4th ed. (Tranquilli, W. J., Thurmon, J. C. and Grimm, K. A. eds.), Blackwell Publishing, Ames.

4. Ishizuka, T., Itami, T., Tamura, J., Saitoh, Y., Saitoh, M., Umar, M. A., Miyoshi, K., Yamashita, K. and Muir, W. W. 2013. Anesthetic and cardiorespiratory effects of propofol, medetomidine, lidocaine and butorphanol total intravenous anesthesia in horses. J. Vet. Med. Sci. 75: 165-172. [Medline] [CrossRef]

5. Kerr, C. L. and Mcdonell, W. N. 2009. Oxygen supplementation and ventilatory support. pp. 332-352. In: Equine Anesthesia Monitoring and Emergensy Therapy 2nd ed. (Muir, W. W. and Hubbell, J. A. E. eds.), Saunders, St. Louis.

6. Kushiro, T., Yamashita, K., Umar, M. A., Maehara, S., Wakaiki, S., Abe, R., Seno, T., Tsuzuki, K., Izumisawa, Y. and Muir, W. W. 2005. Anesthetic and cardiovascular effects of balanced anesthesia using constant rate infusion of midazolam-ketaminemedetomidine with inhalation of oxygen-sevoflurane (MKM-OS anesthesia) in horses. J. Vet. Med. Sci. 67: 379-384. [Medline] [CrossRef]

7. Mama, K. R., Steffey, E. P. and Pascoe, P. J. 1996. Evaluation of propofol for general anesthesia in premedicated horses. Am. J. Vet. Res. 57: 512-516. [Medline]

8. Matot, I., Neely, C. F., Katz, R. Y. and Neufeld, G. R. 1993. Pulmonary uptake of propofol in cats. Effect of fentanyl and halothane. Anesthesiology 78: 1157-1165. [Medline] [CrossRef]

9. Mizuno, Y., Aida, H., Hara, H. and Fujinaga, T. 1994. Cardiovascular effects of intermittent positive pressure ventilation in the anesthetized horse. J. Vet. Med. Sci. 56: 39-44. [Medline] [CrossRef]

10. Muir, W. W. 2009. Anxiolytics, nonopioid sedtive-analgesics, and opioid analgesics. pp.185-209. In: Equine Anesthesia Monitoring and Emergensy Therapy 2nd ed. (Muir, W. W. and Hubbell, J. A. E. eds.), Saunders, St. Louis.

11. Muir, W. W., Skarda, R. T. and Milne, D. W. 1976. Estimation of cardiac output in the horse by thermodilution techniques. Am. J. Vet. Res. 37: 697-700. [Medline]

12. Nolan, A. M. and Hall, L. W. 1985. Total intravenous anaesthesia in the horse with propofol. Equine Vet. J. 17: 394-398. [Medline] [CrossRef]

13. Nyman, G., Frostell, C., Hedenstierna, G., Funkquist, B., Kvart, C. and Blomqvist, H. 1987. Selective mechanical ventilation of dependent lung regions in the anaesthetized horse in dorsal recumbency. Br. J. Anaesth. 59: 1027-1034. [Medline] [CrossRef]

14. Nyman, G. and Hedenstierna, G. 1989. Ventilation-perfusion relationships in the anaesthetised horse. Equine Vet. J. 21: 274-281. [Medline] [CrossRef]

15. Nyman, G., Marntell, S., Edner, A., Funkquist, P., Morgan, K. 
and Hedenstierna, G. 2009. Effect of sedation with detomidine and butorphanol on pulmonary gas exchange in the horse. Acta Vet. Scand. 51: 22. [Medline] [CrossRef]

16. Robinson, N. E. 2009. The respiratory system. pp.11-36. In: Equine Anesthesia Monitoring and Emergency Therapy 2nd ed. (Muir, W. W. and Hubbell, J. A. E. eds.), Saunders, St. Louis.

17. Schwarzwald, C. C., Bonagura, J. D. and Muir, W. W. 2009. The cardiovascular system. pp.37-100. In: Equine Anesthesia Monitoring and Emergensy Therapy 2nd ed. (Muir, W. W. and Hubbell, J. A. E. eds.), Saunders, St. Louis.

18. Senior, J. M. 2013. Morbidity, mortality, and risk of general anesthesia in horses. Vet. Clin. North Am. Equine Pract. 29: 1-18. [Medline] [CrossRef]

19. Steffey, E. P., Wheat, J. D., Meagher, D. M., Norrie, R. D., McKee, J., Brown, M. and Arnold, J. 1977. Body position and mode of ventilation influences arterial $\mathrm{pH}$, oxygen, and carbon dioxide tensions in halothane-anesthetized horses. Am. J. Vet. Res. 38: 379-382. [Medline]

20. Takizawa, E., Ito, N., Ishizeki, J., Goto, F., Hiraoka, H. and Takizawa, D. 2006. The effect of positive end-expiratory pressure ventilation on propofol concentrations during general anesthesia in humans. Fundam. Clin. Pharmacol. 20: 489-492. [Medline] [CrossRef]

21. Umar, M. A., Yamashita, K., Kushiro, T. and Muir, W. W. 3rd. 2007. Evaluation of cardiovascular effects of total intravenous anesthesia with propofol or a combination of ketamine-medetomidine-propofol in horses. Am. J. Vet. Res. 68: 121-127. [Medline] [CrossRef]

22. Wagner, A. E., Bednarski, R. M. and Muir, W. W. 3rd. 1990.
Hemodynamic effects of carbon dioxide during intermittent positive-pressure ventilation in horses. Am. J. Vet. Res. 51: 1922-1929. [Medline]

23. Wagner, A. E., Mama, K. R., Steffey, E. R., Ferreira, T. H. and Rezende, M. L. 2011. Comparison of the cardiovascular effects of equipotent anesthetic doses of sevoflurane plus an intravenous infusion of lidocaine in horses. Am. J. Vet. Res. 72: 452-460. [Medline] [CrossRef]

24. Yamanaka, T., Oku, K., Koyama, H. and Mizuno, Y. 2001. Timerelated changes of the cardiovascular system during maintenance anesthesia with sevoflurane and isoflurane in horses. J. Vet. Med. Sci. 63: 527-532. [Medline] [CrossRef]

25. Yamashita, K., Satoh, M., Umikawa, A., Tsuda, A., Yajima, Y., Tsubakishita, S., Seno, T., Katoh, S., Izumisawa, Y. and Kotani, T. 2000. Combination of continuous intravenous infusion using a mixture of guaifenesin-ketamine-medetomidine and sevoflurane anesthesia in horses. J. Vet. Med. Sci. 62: 229-235. [Medline] [CrossRef]

26. Yamashita, K., Tsubakishita, S., Futaok, S., Ueda, I., Hamaguchi, H., Seno, T., Katoh, S., Izumisawa, Y., Kotani, T. and Muir, W. W. 2000. Cardiovascular effects of medetomidine, detomidine and xylazine in horses. J. Vet. Med. Sci. 62: 1025-1032. [Medline] [CrossRef]

27. Yamashita, K., Wijayathilaka, T. P., Kushiro, T., Umar, M. A., Taguchi, K. and Muir, W. W. 2007. Anesthetic and cardiopulmonary effects of total intravenous anesthesia using a midazolam, ketamine and medetomidine drug combination in horses. J. Vet. Med. Sci. 69: 7-13. [Medline] [CrossRef] 